\title{
Introduction to selected papers from the XXI IMEKO World Congress 2015
}

\author{
Paolo Carbone \\ University of Perugia, Italy
}

Section: EDITORIAL

Citation: Paolo Carbone, Editorial to selected papers from the XXI IMEKO World Congress 2015, Acta IMEKO, vol. 5, no. 4, article 12, December 2016, identifier: IMEKO-ACTA-05 (2016)-04-12

Section Editor: Paul Regtien, The Netherlands

Received December 26, 2016; In final form December 26, 2016; Published December 2016

Copyright: ㄷ 2016 IMEKO. This is an open-access article distributed under the terms of the Creative Commons Attribution 3.0 License, which permits unrestricted use, distribution, and reproduction in any medium, provided the original author and source are credited

Corresponding author: Paolo Carbone, email: paolo.carbone@unipg.it

Dear Reader,

the last papers in this issue were presented at the 2015 IMEKO World Congress 2015 in their original version and then updated and extended for being published in this journal after the usual review process.

The first paper by Maik Rosenberger et al. addresses the subject of measuring geometric parameters using ratiometric cameras. The procedure proposed by the authors follows a standard published by the European Machine Vision Association and presents experimental results aimed at discussing the applicability characteristics of such standard.
The final paper is authored by Petri Österberg et al. and addresses the topic of measurements of moisture in biomaterials using microwaves and NMR. It describes in full detail the procedure followed in both cases and presents experimental results that also include data from the standard Loss-on-Drying method that apparently remains the most accurate and precise among the three approaches.

Have a fruitful reading of the fourth issue of ACTA IMEKO in 2016 ! 